\title{
The Impact of Repeated Treatment with Praziquantel of Schistosomiasis in Children Under Six Years of Age Living in an Endemic Area for Schistosoma haematobium Infection
}

\author{
T Mduluza/ ${ }^{+}$, PD Ndhlovu, TM Madziwa**, N Midzi*, R Zinyama*, \\ CMR Turner***, SK Chandiwana, N Nyazema**, P Hagan***
}

\begin{abstract}
Department of Biochemistry **Department of Pharmacy, University of Zimbabwe, Box MP 167, Mount Pleasant, Harare, Zimbabwe *Blair Research Institute, Harare, Zimbabwe ***Division of Infection and Immunity, University of Glasgow, Glasgow, UK
\end{abstract}

Praziquantel was given every eight weeks for two years to children aged under six years of age, living in a Schistosoma haematobium endemic area. Infection with S. haematobium and haematuria were examined in urine and antibody profiles (IgA, $\operatorname{IgE}$, IgM, IgG1, IgG2, IgG3, and IgG4) against S. haematobium adult worm and egg antigens were determined from sera collected before each treatment. Chemotherapy reduced infection prevalence and mean intensity from $51.8 \%$ and 110 eggs per $10 \mathrm{ml}$ urine, respectively, before starting re-treatment programme to very low levels thereafter. Praziquantel is not accumulated after periodic administration in children. Immunoglobulin levels change during the course of treatment with a shift towards 'protective' mechanisms. The significant changes noted in some individuals were the drop in 'blocking' IgG2 and IgG4 whereas the 'protecting' IgA and IgG1 levels increased. The antibody profiles in the rest of the children remained generally unchanged throughout the study and no haematuria was observed after the second treatment. The removal of worms before production of large number of eggs, prevented the children from developing morbidity.

Key words: Schistosoma haematobium - praziquantel - antibody profiles - morbidity

Information on schistosomiasis infection from a number of different geographical settings indicates that infection intensities and the development of immunological resistance to infection are related, in some way, to age (Butterworth et al. 1984, 1985, 1991, 1992, Hagan et al. 1987, 1991, Wilkins et al. 1987, Dessein et al. 1992, Roberts et al. 1993). Infection levels are normally highest in children and following chemotherapeutic cure, children are more rapidly reinfected and at higher rates than older children and adults (Wilkins et al. 1987, Butterworth et al. 1992). These higher rates of reinfection are in part related to higher levels of water contact by children, a feature characteristic of the majority of endemic settings. While the severe clinical forms of schistosomiasis infection may take many years to develop, there is general agreement that targeting treatment to children can make a considerable impact on the development of pathology (Kloetzel 1967, Sturrock 1987). The use of chemotherapy to control schisto-

\footnotetext{
${ }^{+}$Corresponding author. E-mail: mduluza@blair.co.zw / mduluza@hotmail.com Received 14 May 2001

Accepted 25 July 2001
}

somiasis is usually based on annual rounds of screening and treatment. In many endemic settings this has been successful but in areas of intense transmission more frequent interventions could ensure a greater impact on infection levels.

Chemotherapy-induced changes in responses to infection have been reported on a number of occasions (Sturrock et al. 1983, Butterworth et al. 1991, Demeure et al. 1993, Roberts et al. 1993, Grogan et al. 1995, 1996), often as an increased lymphoproliferative ability of peripheral blood mononuclear cells (PBMC) collected after treatment. The impact of frequent repeated treatments on immunological responses to schistosome infection have, however, never been reported, especially in children under six years of age. Whether repeated treatments block the development of protective immune responses to infection or accelerate the development of protective immune responses has yet to be established. Studies of the effects of chemotherapy on other (intestinal) helminths indicate that the drug treatment can facilitate the development of resistance to re-infection. Even if chemotherapy shows the development of immunological responses, this may be counterbalanced by the benefits to be gained from the reduction in levels of pathology arising from infection. 
A child born in an area where schistosomiasis is endemic can be expected to harbour worms for most of his or her life owing to repeated exposure to infection, although some protective immunity is likely to develop, depending on exposure of the infectious agent (Woolhouse et al. 1991). Schistosomes are known to survive in the host for long periods, despite the development of concomitant immunity. A key characteristic of schistosomiasis promoting this longevity is the development of several mechanisms by which the parasites evade or modulate the host's immunological attack. Since parasites and hosts may co-exist for lengthy periods, this might indicate that some degree of immunological tolerance or anergy become induced. It is because of the longevity of infection that the disease causes serious chronic morbidity rather than acute mortality with severity related to worm burdens to which is related egg. In addition to the longevity of individual infections, there is also persistence of infection due to repeated re-infection throughout the host life.

Effective vaccines are a long way from being developed, even when good candidates have been identified, they may take many years to pass through pre-clinical trials (Bergquist 1995). In the absence of a vaccine, the most effective current method to combat the scourge of schistosomiasis is through targeted chemoprophylaxis of children (Hagan et al. 1994). Even after mass chemotherapy, as reported from several programmes, the children become reinfected with heavy intensities such that there is a need for improved early diagnosis and treatment of young children in endemic areas who seem to lack developed immune systems against the disease (Sturrock et al. 1983, Wilkins et al. 1984b). A possible method to combat this problem would be to keep the children under staggered treatment until they are of an age where they are capable to develop their own protective immunity.

The children in this study would have continued to have exposure to infection and therefore be exposed to repeated parasite challenges. The timing of the chemotherapy was designed to remove any adult worms which may have developed after the preceding treatment therefore minimising the number of eggs which may have been produced and thus reducing exposure of the children to egg antigens. The hypothesis on which this study was based was that the continued exposure to the worm antigens released by the praziquantel treatment, would result in the development of protective immunological responses, but the prevention of deposition of large numbers of eggs would ablate development of immunopathology. To monitor antischistosome responses, the children were examined for development of potentially protective, schistosome-specific antibody isotypes.

\section{MATERIALS AND METHODS}

Study area and population - The study was carried out in an area called Madziwa situated in the high veld region in north eastern Zimbabwe. The area is rural, and the people depend on seasonal small-scale commercial and subsistence farming. Villagers have unlimited use of river water.

Parasitology, blood sampling and treatment Urine samples for parasitological diagnosis for $S$. haematobium infections were collected from 595 children on three consecutive days and were processed on the day of collection. Urine samples were examined by filtration technique (Mott et al. 1982). Infection expressed as eggs/10 $\mathrm{ml}$ of urine. Stool samples were examined by the Kato-Katz technique (as modified by Peters et al. 1980). Those found to be infected with $S$. mansoni were excluded from the study.

Up to $2 \mathrm{ml}$ of venous blood was collected. After blood collection, the children were treated with 40 $\mathrm{mg} / \mathrm{kg}$ body weight regardless of their infection status. The proceedure was repeated every eight weeks.

ELISA determination of antibody isotypes - $S$. haematobium egg and worm antigens were obtained from the Schistosome Biological Supply Programme, Theodore Bilharz Research Institute, Giza (Egypt). These were reconstituted to whole worm homogenate (WWH) and soluble egg antigens (SEA). The ELISA detection of anti-worm and anti-egg antibodies was carried out using a protocol similar to that described by Mutapi et al. (1998).

Praziquantel determination in sera - Serum from children treated with praziquantel was used to determine the unchanged praziquantel. Each $1 \mathrm{ml}$ portion of serum was extracted for unchanged praziquantel three times with $2 \mathrm{ml}$ ethyl acetate. The three ethyl acetate extracts were pooled and reduced to dryness by blowing air over the extracts in tubes placed in a water bath at $60^{\circ} \mathrm{C}$. Six vials containing $10 \mathrm{ml}$ of blood had $50 \mu \mathrm{g}$ of pure praziquantel placed in them. These spiked' samples of blood were thoroughly mixed using a vortex mixer for $5 \mathrm{~min}$. The amount of praziquantel recovered was then determined by high performance liquid chromatography (HPLC). Pure praziquantel obtained from Bayer was used as standards at $1,5,10$, and $20 \mu \mathrm{g} / \mathrm{ml}$ were made by serial dilution with the mobile phase. Absorbance of the six standard solutions was read off a shimadzu uv-visible spectrophotometer set at a wavelength of $210 \mathrm{~nm}$.

Detection was with a uv-visible absorbance detector set at $210 \mathrm{~nm}$ and a run time of $10 \mathrm{~min}$ was set. The mobile phase was then run through the column until a steady baseline was obtained. $50 \mu \mathrm{l}$ of each of the six standard solutions was injected into the HP 1050 series HPLC in turn. The dry samples obtained from the blood were reconstituted 
in $200 \mu \mathrm{l}$ of the HPLC mobile phase. After spinning down of the vials with a vortex mixer, $50 \mu$ of the sample was drawn from the middle of the vial and then injected into the HPLC for the determination of unchanged praziquantel.

\section{RESULTS}

Parasitology and treatment - Results from preliminary parasitological surveys of the children attending schools near the pre-school centres indicated that the area had high $S$. haematobium infection with low $S$. mansoni infection (Table I). At the beginning of the study, before treatment, the prevalence of infection was $51.8 \%$ (Table II). The figure was different for the follow-up prevalences after treatment, which were below $7 \%$ with the last examination showing only three re-infected children. The intensity of infection of the cohort was moderate before treatment giving a mean egg count of 18 ep10 ml urine. After treatment the intensity of infection was less than $4 \mathrm{ep} 10 \mathrm{ml}$ of urine at 2 months and 9 ep $10 \mathrm{ml}$ of urine by four months. Thereafter infection intensity was below 2 ep $10 \mathrm{ml}$ of urine examined.

Antibody response profiles with time - Prior to praziquantel treatment, the antibody responses of both infected and uninfected children to WWH and
SEA antigens showed similar patterns. There were high correlations, of anti-egg IgE and anti-egg IgG4 to infection intensity measured as egg output at the start of the programme (Table III, Spearman's rank correlation $\mathrm{p}=0.013$ and $\mathrm{p}=001$ for $\operatorname{IgE}$ and $\operatorname{IgG} 4$, respectively). The infected children showed a high correlation of anti-egg IgG4 to egg output and antiworm IgM to egg output ( $p<0.0001$ and $p=0.035$, respectively, Table III). Correlations were observed between infection intensity (egg output) and antiegg IgA and IgG4 ( $\mathrm{p}=0.050$ and $\mathrm{p}=0.027$, respectively) at four months after treatment. At 10 months, egg output and anti-egg IgE were positively correlated $(p=0.032)$. No correlations were found at other time points. In general the patterns of the antibody isotypes profiles to WWH and SEA antigens were similar throughout the repeated treatment programme (Tables IV, V). Differences were noted between the anti-worm IgE and anti-egg IgE responses. Higher levels of anti-egg $\operatorname{IgE}$ antibodies were detected than anti-worm IgE antibodies throughout the study. Antiegg IgG3 and anti-egg IgG2 antibodies were detected at lower levels than any of the other isotypes at all of the examination time points.

The blood samples obtained from the followup, none showed any amount of praziquantel. Praziquantel does not accumulate and the benefit

TABLE I

Results of a preliminary parasitology survey from six schools in the Madziwa area marking each central point in the catchment area for the study

\begin{tabular}{lcccc}
\hline School centre & $\begin{array}{c}\text { No. children } \\
\text { examined }\end{array}$ & $\begin{array}{c}\text { Schistosoma haematobium } \\
\text { prevalence } \%(\mathrm{n})\end{array}$ & $\begin{array}{c}\text { No. children } \\
\text { examined }\end{array}$ & $\begin{array}{c}\text { Schistosoma mansoni } \\
\text { Prevalence } \%(\mathrm{n})\end{array}$ \\
\hline Madziwa & 97 & $42.7(41)$ & 86 & $4.6(4)$ \\
Chihuri & 95 & $71.6(68)$ & 100 & $18(18)$ \\
Mupfure & 90 & $90(81)$ & 74 & $28.4(21)$ \\
Nyamaruro & 97 & $66(64)$ & 96 & $14.6(14)$ \\
Chimbira & 99 & $61.6(61)$ & 97 & $12.4(12)$ \\
Kaziro & 99 & $58.6(58)$ & 97 & $7.2(7)$ \\
\hline Total & 577 & $64.6(373)$ & 550 & $13.8(76)$ \\
\hline
\end{tabular}

\section{TABLE II}

Number of children examined for Schistosoma haematobium infection and number of children in the humoral assays cohort after parasitology examination and provision of blood samples. The numbers shown represents the total number of children assayed for the antibody isotype at each follow-up time point and in each infection status group

\begin{tabular}{cccc}
\hline $\begin{array}{l}\text { Follow-up time } \\
\text { (months) }\end{array}$ & $\begin{array}{c}\text { Total number } \\
\text { examined }\end{array}$ & Prevalence \% (n) & $\begin{array}{c}\text { Infection intensity } \\
\text { ep10 ml }\end{array}$ \\
\hline Start (Pre-treatment) & 595 & $51.8(357)$ & 110 \\
2 & 465 & $6.7(32)$ & 4 \\
4 & 567 & $6(34)$ & 9 \\
6 & 209 & $2.4(5)$ & 2 \\
8 & 220 & $2.3(5)$ & 3 \\
10 & 230 & $2.2(5)$ & 3 \\
14 & 246 & $1.2(3)$ & 2 \\
\hline
\end{tabular}


TABLE III

The correlation between different antibody isotype profiles to egg output (infection) at each examination and treatment point

\begin{tabular}{lcccccccccc}
\hline & \multicolumn{3}{c}{ Before treatment } & \multicolumn{3}{c}{2 months after } & \multicolumn{3}{c}{4 months after } \\
\hline $\begin{array}{l}\text { Antibody } \\
\text { isotype }\end{array}$ & No. & $\begin{array}{c}\text { Spearman } \\
\text { coefficient }\end{array}$ & P-value & No. & $\begin{array}{c}\text { Spearman } \\
\text { coefficient }\end{array}$ & P-value & No. & $\begin{array}{c}\text { Spearman } \\
\text { coefficient }\end{array}$ & P-value \\
\hline Anti-egg & & & & & & & & & & \\
IgA & 83 & -0.0931 & 0.402 & 35 & 0.0910 & 0.603 & 66 & -0.2421 & $\mathbf{0 . 0 5}$ \\
IgE & 83 & 0.2705 & $\mathbf{0 . 0 1 3}$ & 35 & -0.3990 & $\mathbf{0 . 0 1 8}$ & 49 & 0.3070 & $\mathbf{0 . 0 3 2}$ \\
IgG1 & 31 & 0.1120 & 0.549 & 13 & 0.1572 & 0.608 & 21 & 0.0000 & 1.000 \\
IgG2 & 56 & 0.1587 & 0.243 & 23 & -0.3574 & 0.094 & 43 & 0.0786 & 0.616 \\
IgG3 & 23 & -0.0067 & 0.976 & 7 & 0.1786 & 0.702 & 16 & -0.3349 & 0.205 \\
IgG4 & 83 & 0.3571 & $\mathbf{0 . 0 0 1}$ & 35 & 0.1322 & $\mathbf{0 . 4 4 9}$ & 62 & 0.2810 & $\mathbf{0 . 0 2 7}$ \\
IgM & 83 & 0.1163 & 0.295 & 35 & -0.2690 & 0.118 & 66 & 0.2157 & 0.902 \\
Anti-worm & & & & & & & & & & \\
IgA & 83 & 0.0762 & 0.494 & 35 & 0.0838 & 0.632 & 66 & -0.0546 & 0.664 \\
IgE & 83 & 0.3695 & $\mathbf{0 . 0 0 1}$ & 35 & -0.0698 & 0.690 & 55 & 0.3453 & $\mathbf{0 . 0 1 0}$ \\
IgG4 & 83 & 0.0589 & 0.597 & 35 & 0.2238 & 0.196 & 66 & 0.0468 & 0.709 \\
IgM & 83 & -0.0494 & 0.657 & 35 & -0.0430 & 0.806 & 65 & -0.0886 & 0.483 \\
\hline
\end{tabular}

in preventing recurrent schistosomiasis infection was observed during the follow-up time period. Very few subjects developed mild schistosomiasis (Table II). This could lead to postulate that pharmacokinetic half life is not such an important factor but the 'killing time'. Gentamycin is an important example of this phenomenon that has a plasma half life of between 2 to $3 \mathrm{~h}$ and yet has a post antibiotic effect of $3 \mathrm{~h}$. Praziquantel has an invasion half life of 0.1 to $0.3 \mathrm{~h}$. Rapid invasion occurs as praziquantel is lipophilic and can penetrate the tegumental membrane of the parasite with ease. Drug uptake is reversible with 45 to $93 \%$ being lost from the schistosomes after transfer to a drug free medium within 5 to $30 \mathrm{~min}$. Further evidence to indicate that protracted plasma levels of praziquantel are not necessary in subject on repeated treatment as demonstrable concentration in the blood could not be detected but still got infected and developed clinical disease (Table II).

\section{DISCUSSION}

The results from the preliminary examinations indicated that the area has a major problem of schistosomiasis. Children in the area were heavily exposed to infection. The high infection levels were also noted among the young children as depicted by the high prevalence of infection coupled with heavy infection intensities. Reasons given for high infection levels in these young children were that the children accompanied their mothers to the rivers during their daily activities of tending vegetable gardens and some domestic chores like washing dishes and clothes and also bathing. These activities exposed the children to cercaria infested water.
The absence of major variations in the antibody isotypes with time was probably due to the young age of the children. Development of demonstrable protective immunity has been reported to take place in older children above 10 years old (Rihet et al. 1991, Dessein et al. 1992, Ndhlovu et al. 1996). The correlations of IgE and IgG4 antibodies with infection probably indicates that they are a marker of infection intensity in children under 6 years of age (Hagan et al. 1991). Of the two isotypes, IgE which in older individuals is associated with resistance to infection, was detected at higher levels compared with the IgG4 in response to egg antigen. As IgE evolved to fight parasitic infections, it is no surprise that IgE was noted at higher levels than IgG4. It may be possible that development of protective immunity is not only duration of exposure and infection intensity dependent, but age may also be necessary on which will depend the experience of schistosome parasite infection. This later point may support the report that residents in a new $S$. mansoni epidemic focus in Senegal (Gryseels et al. 1994, 1995) lacked clear developed protective immunity after treatment irrespective of age suggesting that experience of infection acquired over a long period plays a major role in the development of protective immunity.

The resistance to reinfection is based on immunological responses as there is a $90-95 \%$ reduction in egg count in one year after a single dose of praziquantel (Webster et al. 1997). Repeated dosing would prevent signs of pathology by killing larval worms whilst children continue being exposed to infection. These children in turn would fail to experience an adult worm burden and gain resis- 
TABLE IV

Antibody isotype profiles (O.D @ 492 nm) before and after giving chemotherapeutical cure with praziquantel. The table shows uninfected children and infected children at each follow-up time point and the measurements are Schistosoma haematobium egg-specific serum antibody levels determined by ELISA

\begin{tabular}{|c|c|c|c|c|c|c|c|c|}
\hline \multirow[b]{3}{*}{ Time in months } & \multicolumn{2}{|c|}{ Antibody isotype levels } & \multicolumn{2}{|c|}{ Mean O.D ( $95 \%$ CI) } & & & & \\
\hline & \multicolumn{2}{|c|}{$\operatorname{Ig} \mathrm{A}$} & \multicolumn{2}{|c|}{ IgE } & \multicolumn{2}{|c|}{ IgG1 } & \multicolumn{2}{|c|}{ IgG2 } \\
\hline & Uninfected & Infected & Uninfected & Infected & Uninfected & Infected & Uninfected & Infected \\
\hline Before treatment & $\begin{array}{c}0.28 \\
(0.25-0.32)\end{array}$ & $\begin{array}{c}0.25 \\
(0.21-0.29)\end{array}$ & $\begin{array}{c}0.45 \\
(0.38-0.47)\end{array}$ & $\begin{array}{c}0.57 \\
(0.51-0.62)\end{array}$ & $\begin{array}{c}0.31 \\
(0.3-0.47)\end{array}$ & $\begin{array}{c}0.55 \\
(0.48-0.62)\end{array}$ & $\begin{array}{c}0.10 \\
(0.7-0.12)\end{array}$ & $\begin{array}{c}0.11 \\
(0.09-0.15)\end{array}$ \\
\hline 2 & $\begin{array}{c}0.21 \\
(0.19-0.25)\end{array}$ & $\begin{array}{c}0.22 \\
(0.18-0.25)\end{array}$ & $\begin{array}{c}0.50 \\
(0.46-0.54)\end{array}$ & $\begin{array}{c}0.50 \\
(0.46-0.54)\end{array}$ & $\begin{array}{c}0.46 \\
(0.37-0.56)\end{array}$ & $\begin{array}{c}0.46 \\
(0.37-0.56)\end{array}$ & $\begin{array}{c}0.07 \\
(0.05-0.10)\end{array}$ & $\begin{array}{c}0.07 \\
(0.06-0.10)\end{array}$ \\
\hline 4 & $\begin{array}{c}0.26 \\
(0.23-0.29)\end{array}$ & $\begin{array}{c}0.26 \\
(0.23-0.29)\end{array}$ & $\begin{array}{c}0.48 \\
(0.44-0.52)\end{array}$ & $\begin{array}{c}0.48 \\
(0.44-0.52)\end{array}$ & $\begin{array}{c}0.52 \\
(0.45-0.58)\end{array}$ & $\begin{array}{c}0.52 \\
(0.45-0.58)\end{array}$ & $\begin{array}{c}0.10 \\
(0.08-0.12)\end{array}$ & $\begin{array}{c}0.10 \\
(0.08-0.12)\end{array}$ \\
\hline 6 & $\begin{array}{c}0.23 \\
(0.19-0.23)\end{array}$ & $\begin{array}{c}0.23 \\
(0.19-0.25)\end{array}$ & $\begin{array}{c}0.47 \\
(0.42-0.53)\end{array}$ & $\begin{array}{c}0.47 \\
(0.42-0.53)\end{array}$ & $\begin{array}{c}0.48 \\
(0.41-0.55)\end{array}$ & $\begin{array}{c}0.48 \\
(0.41-0.55)\end{array}$ & $\begin{array}{c}0.11 \\
(0.08-0.13)\end{array}$ & $\begin{array}{c}0.11 \\
(0.08-0.13)\end{array}$ \\
\hline 8 & $\begin{array}{c}0.25 \\
(0.22-0.29)\end{array}$ & $\begin{array}{c}0.24 \\
(0.22-0.29)\end{array}$ & $\begin{array}{c}0.44 \\
(0.39-0.50)\end{array}$ & $\begin{array}{c}0.44 \\
(0.38-0.50)\end{array}$ & $\begin{array}{c}0.49 \\
(0.42-0.57)\end{array}$ & $\begin{array}{c}0.49 \\
(0.42-0.57)\end{array}$ & $\begin{array}{c}0.10 \\
(0.08-0.12)\end{array}$ & $\begin{array}{c}0.10 \\
(0.08-0.13)\end{array}$ \\
\hline 10 & $\begin{array}{c}0.22 \\
(0.19-0.26)\end{array}$ & $\begin{array}{c}0.22 \\
(0.19-0.25)\end{array}$ & $\begin{array}{c}0.44 \\
(0.39-0.50)\end{array}$ & $\begin{array}{c}0.44 \\
(0.39-0.50)\end{array}$ & $\begin{array}{c}0.51 \\
(0.43-0.58)\end{array}$ & $\begin{array}{c}0.51 \\
(0.43-0.58)\end{array}$ & $\begin{array}{c}0.09 \\
(0.07-0.12)\end{array}$ & $\begin{array}{c}0.09 \\
(0.07-0.12)\end{array}$ \\
\hline \multirow[t]{3}{*}{14} & $\begin{array}{c}0.22 \\
(0.17-0.27) \\
\end{array}$ & $\begin{array}{c}0.22 \\
(0.17-0.27) \\
\end{array}$ & $\begin{array}{c}0.49 \\
(0.40-0.57) \\
\end{array}$ & $\begin{array}{c}0.48 \\
(0.40-0.57)\end{array}$ & $\begin{array}{c}0.36 \\
(0.25-0.46) \\
\end{array}$ & $\begin{array}{c}0.34 \\
(0.25-0.46) \\
\end{array}$ & $\begin{array}{c}0.08 \\
(0.06-0.10) \\
\end{array}$ & $\begin{array}{c}0.08 \\
(0.06-0.10)\end{array}$ \\
\hline & \multicolumn{2}{|c|}{ Antibody isotype levels } & \multicolumn{2}{|c|}{ Mean O.D (95 \% C I) } & & & & \\
\hline & \multicolumn{2}{|c|}{ IgG3 } & \multicolumn{2}{|c|}{ IgG4 } & \multicolumn{2}{|c|}{$\operatorname{IgM}$} & & \\
\hline Time in months & Uninfected & Infected & Uninfected & Infected & Uninfected & Infected & & \\
\hline Before treatment & $\begin{array}{c}0.12 \\
(0.08-0.17)\end{array}$ & $\begin{array}{c}0.12 \\
(0.05-0.18)\end{array}$ & $\begin{array}{c}0.29 \\
(0.25-0.34)\end{array}$ & $\begin{array}{c}0.35 \\
(0.31-0.39)\end{array}$ & $\begin{array}{c}0.44 \\
(0.40-0.48)\end{array}$ & $\begin{array}{c}0.50 \\
(0.42-0.58)\end{array}$ & & \\
\hline 2 & $\begin{array}{c}0.13 \\
(0.08-0.17)\end{array}$ & $\begin{array}{c}0.13 \\
(0.04-0.21)\end{array}$ & $\begin{array}{c}0.32 \\
(0.25-0.34)\end{array}$ & $\begin{array}{c}0.32 \\
(0.27-0.36)\end{array}$ & $\begin{array}{c}0.48 \\
(0.40-0.48)\end{array}$ & $\begin{array}{c}0.48 \\
(0.43-0.52)\end{array}$ & & \\
\hline 4 & $\begin{array}{c}0.12 \\
(0.09-0.14)\end{array}$ & $\begin{array}{c}0.12 \\
(0.05-0.18)\end{array}$ & $\begin{array}{c}0.26 \\
(0.23-0.29)\end{array}$ & $\begin{array}{c}0.26 \\
(0.31-0.39)\end{array}$ & $\begin{array}{c}0.47 \\
(0.44-0.51)\end{array}$ & $\begin{array}{c}0.47 \\
(0.43-0.58)\end{array}$ & & \\
\hline 6 & $\begin{array}{c}0.10 \\
(0.06-0.14)\end{array}$ & $\begin{array}{c}0.10 \\
(0.06-0.14)\end{array}$ & $\begin{array}{c}0.30 \\
(0.26-0.34)\end{array}$ & $\begin{array}{c}0.30 \\
(0.26-0.34)\end{array}$ & $\begin{array}{c}0.44 \\
(0.41-0.48)\end{array}$ & $\begin{array}{c}0.44 \\
(0.41-0.48)\end{array}$ & & \\
\hline 8 & $\begin{array}{c}0.11 \\
(0.09-0.13)\end{array}$ & $\begin{array}{c}0.11 \\
(0.09-0.13)\end{array}$ & $\begin{array}{c}0.26 \\
(0.22-0.30)\end{array}$ & $\begin{array}{c}0.26 \\
(0.22-0.30)\end{array}$ & $\begin{array}{c}0.49 \\
(0.42-0.56)\end{array}$ & $\begin{array}{c}0.49 \\
(0.42-0.56)\end{array}$ & & \\
\hline 10 & $\begin{array}{c}0.10 \\
(0.06-0.14)\end{array}$ & $\begin{array}{c}0.10 \\
(0.06-0.14)\end{array}$ & $\begin{array}{c}0.25 \\
(0.22-0.28)\end{array}$ & $\begin{array}{c}0.25 \\
(0.22-0.28)\end{array}$ & $\begin{array}{c}0.46 \\
(0.42-0.50)\end{array}$ & $\begin{array}{c}0.46 \\
(0.42-0.50)\end{array}$ & & \\
\hline 14 & $\begin{array}{c}0.09 \\
(0.04-0.13)\end{array}$ & $\begin{array}{c}0.09 \\
(0.04-0.13)\end{array}$ & $\begin{array}{c}0.26 \\
(0.21-0.30)\end{array}$ & $\begin{array}{c}0.26 \\
(0.21-0.30)\end{array}$ & $\begin{array}{c}0.42 \\
(0.37-0.47)\end{array}$ & $\begin{array}{c}0.42 \\
(0.37-0.47)\end{array}$ & & \\
\hline
\end{tabular}




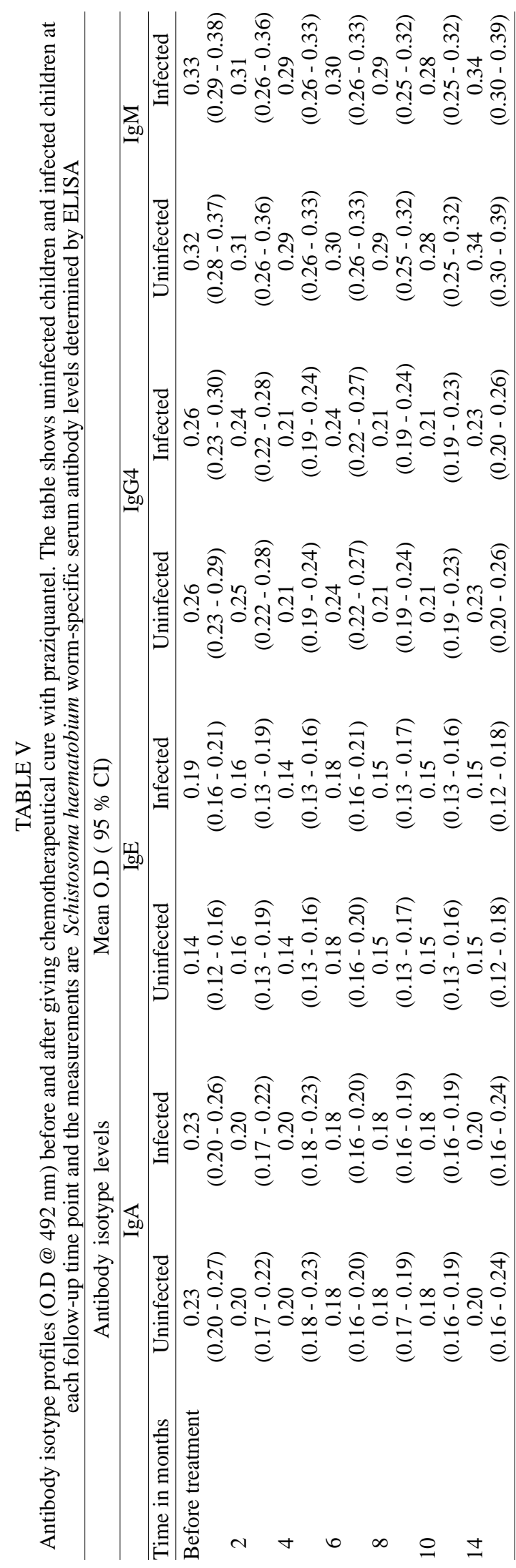

tance by frequent removal of worms and the consequent absence of egg antigens and ensue pathology.

Treatment for schistosomiasis should concentrate on reduction of morbidity and immunopathology. Mass chemotherapy is one form of treatment whereby the entire population is treated without prior individual diagnosis. The advantage is low diagnostic cost but high cost of drugs and the delivery system may be the major constraints. Selective chemotherapy may be offered after extensive screening to only those who are schistosome positive. Costliness of screening can be partially offset by decreased cost of drugs. Targeted chemotherapy is recommended in endemic areas where only those with high egg counts are targeted as they are likely to suffer from morbidity and contaminate the environment. The majority of people have light infections and thus have a much better prognosis. Low drug costs but extremely high diagnostic costs are factors to be considered.

Epidemiological studies in different endemic areas indicated that the prevalence and intensity of S. haematobium infection rise during the first 15 years of life and decline to low levels amongst the older individuals. Immunoregulatory mechanisms that operate in S. haematobium infected adults differ from those in infected children as shown by the plasma levels of antibodies. Levels of IgG4 against worm and egg antigens were found to be high in children and lower in the older age groups whilst specific IgE antibody responses were low in children and higher in adults (Grogan et al. 1996, Hagan et al., 1991). IgG4 is known to interfere with IgE mediated mast cell degranulation and may therefore reduce the harmful consequences of any schistosome induced allergic reactions. IgG4 will also block IgG1 and IgG3 mediated killing of schistosomula by human eosinophils in vitro. Therefore, it has been suggested that younger children remain susceptible to reinfection due to the high levels of blocking antibody responses that prevent the expression of the protective mechanisms. These blocking antibodies may include IgM and $\mathrm{IgG}$ isotypes. Thus infection levels and immune responses are interdependent and both are related to age and exposure.

Praziquantel is not accumulated after periodic administration in children. Immunoglobulin levels do not change during the course of treatment with a shift towards 'protective' mechanisms. In young children there is no significant change between the documented blocking antibodies and protective antibodies. However, treatment every eight weeks prevents morbidity from developing through elimination of worms before getting established and laying eggs, which in turn would cause immunopathology. 


\section{REFERENCES}

Butterworth AE, Bensted-Smith R, Capron A, Capron M, Dalton PR, Dunne DW, Gryzch J, Kariuki HC, Khalife J, Koech D, Mugambi M, Ouma JH, ArapSiongok TK, Sturrock RF 1987. Immunity in human schistosomiasis mansoni. Prevention by blocking antibodies of expression of immunity in young children. Parasitology 94: 281-300.

Butterworth AE, Capron M, Cordingley JS, Dalton PR, Dunne DW, Kariuki HC, Kimani G, Koech D, Mugambi M, Ouma JH, Prentice MA, Richardson BA, Arap-Siongok TK, Sturrock RF, Taylor DW 1985. Immunity after treatment of human schistosomiasis mansoni. ii. Indentification of resistant individuals, and analysis of their immune responses. Trans $R$ Soc Trop Med Hyg 79: 393-408.

Butterworth AE, Dalton PR, Dunne DW, Mugambi M, Ouma JH, Richardson BA, Arap Siongok TK, Sturrock RF 1984. Immunity after treatment of human schistosomiasis mansoni. I. Study Design, pretreatment observations and the results of treatment. Trans $R$ Soc Trop Med Hyg 78: 108-123.

Butterworth AE, Dunne DW, Fulford AJC, Thorne KJI, Gachuhi K, Ouma JH, Sturrock RF 1992. Human immunity to Schistosoma mansoni: observation on mechanism, and implications for control. Immunol Invest 21: 391-396.

Butterworth AE, Sturrock RF, Ouma JH, Mbugua GG, Fulford AJC, Kariuki HC, Koech D 1991. Comparison of different chemotherapy strategies against Schistosoma mansoni in Machakos District, Kenya: Effects on human infection and morbidity. Parasitology 103: 339-344.

Demeure CE, Rihet P, Abel L, Quattara M, Bourgois A, Dessein AJ 1993. Resistance to S. mansoni in humans - Influence of the IgE/IgG4 balance and IgG2 in immunity to reinfection after chemotherapy. J Infect Dis 168: 1000-1008.

Dessein AJ, Demeure CE, Rihet P, Kohlstaedt S, Carneiro-Carvalho D, Ouattara M, Goudot-Crozel V, Dessein H, Bourgois A, Abel L, Carvallo EM, Prata A 1992. Environmental, genetic and immuniological factors in human resistance to Schistosoma mansoni. Immunol Invest 21: 423-453.

Grogan JL, Kremsner PG, van Dam GJ, Metzger W, Mordmuller B, Deelder AM, Yazdanbakhsh M 1996. Antischistosome IgG4 and IgE responses are affected differentially by chemotherapy in children versus adults. J Infect Dis 173.

Gryseels B, Nkulikyinka L, Engels D 1994. Impact of repeated community-based selective chemotherapy on morbidity due to schistosomiasis mansoni. Am J Trop Med Hyg 51: 634-641.

Gryseels B, Stelma F, Talla I, Polman K, Van Dam G, Sow S, Diaw M, Sturrock RF, Decam C, Niang M, Doehring-Schwerdtfeger E, Kardorff R 1995. Epidemiology, immunology and chemotherapy of Schistosoma mansoni infections in a recently exposed community in Senegal. Trop Geo Med 46: 209-219.

Hagan P, Blumenthal JU, Dunn D, Simpson AJ, Wilkins
HA 1991. Human IgE, IgG4 and resistance to infection with Schistosoma haematobium. Nature 349: 243-245.

Hagan P, Blumenthal UJ, Chaudri M, Greenwood BM, Hayes RJ, Hodgson J, Kelly C, Knight M, Simpson AJG, Smither SR, Wilkins HA 1987. Resistance to reinfection with Schistosoma haematobium in Gambian children: analysis of their immune response. Trans $R$ Soc Trop Med Hyg 81: 938-946.

Hagan P, Chandiwana SK, Ndhlovu P, Woolhouse M, Dessein AJ 1994. The epidemiology, immunology and morbidity of Schistosoma haematobium infections in diverse communities in Zimbabwe. The study design. Trop Geo Med 46: 227.

Katz N, Chaves A, Pellegrino J 1972. A simple device of quantitative stool thick smear technique in Schistosoma mansoni. Rev Inst Med Trop São Paulo 14: 397-400.

Kloetzel K 1967. A rationale for the treatment of Schistosoma mansoni even when reinfection is expected. Trans $R$ Soc Trop Med Hyg 61: 609-610.

Mott KE, Baltes R, Bambagha J, Baldassini B 1982. Field studies of the reusable polyamide filter for detection of $S$. haematobium eggs by urine filtration. Propernmedlizin and Parasitologie 33: 227-228.

Mutapi F, Ndhlovu PD, Hagan P, Spicer JT, Mduluza T, Turner CRM, Chandiwana SK, Woolhouse MEJ 1998. Chemotherapy accelerates the development of acquired immune responses to Schistosoma haematobium infection. J Infec Dis 178: 289-293.

Ndhlovu P, Cadman H, Vennervald BJ, Christensen NO, Chidimu M, Chandiwana SK 1996. Age-related antibody profiles in Schistosoma haematobium infections in a rural community in Zimbabwe. Parasite Immunol 18: 181-191.

Peters PA, El Alany M, Warren KS, Mahmoud FA 1980. Quick Kato smear for field quantification of $S$. mansoni eggs. Am J Trop Med Hyg 29: 217-219.

Rihet P, Demeure CE, Bourgois PA, Dessein AJ 1991. Evidence for an association between human resistance to $S$. mansoni and high anti-larval IgE levels. Eur J Immunol 11: 2679-2686.

Roberts M, Butterworth AE, Kimani G, Kamau T, Fulford AJC, Dunne DW, Ouma JH, Sturrock RF 1993. Immunity after treatment of human schistosomiasis: association between cellular responses and resistance to reinfection. Infect Immun 61: 4984-4993.

Sturrock RF, Kimani G, Cottrell BJ, Butterworth AE, Seitz HM, Siongok TK, Houba V 1983. Observations on possible immunity to reinfection among Kenyan schoolchildren after treatment for Schistosoma mansoni. Trans $R$ Soc Trop Med Hyg 77: 3341.

Webster M, Fallon PG, Fulford AJC, Butterworth AE, Ouma JH, Kimani G, Dunne DW 1997. Effect of praziquantel and oxamniquine treatment on human isotype responses to Schistosoma mansoni: elevated IgE to adult worm. Parasite Immunol 19: 333-335.

Wilkins HA, Blumenthal UJ, Hagan P, Tulloch S, Hayes RJ 1987. Resistance to reinfection after treatment for urinary schistosomiasis. Trans $R$ Soc Trop Med 
164 Treatment with Praziquantel - T Mduluza et al.

Hyg 81: 29-35.

Wilkins HA, Goll PH, Marshall TFD, Moore PJ 1984b. Dynamics of Schistosoma haematobium infection in a Gambian Community. III. Acquisition and loss of infection. Trans R Soc Trop Med Hyg 78: 227-232. Woolhouse M, Taylor P, Matanhire D, Chandiwana SK 1991. Acquired immunity and epidemiology of Schistosoma haematobium. Nature 351: 757-759. 